\title{
Significance of Women Education in the Process of Social Evolution
}

\author{
Fatima Ali \\ Lecturer \\ Department of History \& Pakistan Studies \\ The Women University Multan
}

\begin{abstract}
:
Women education is enduring many blistering issues including the gender inequality, religious factors, conservative approach and patriarchy in Pakistan. It is understandable that education is external and always imposes from the outer world.The main concern of this research paper is that through the improvement of women's education, one can command over the hurdles of society and eliminate the social evils in Pakistan. Females direct involves in the process of socialization of children, they are playing a vital role in this regard of promoting peace in society. As well as the ignoranceof ratio of women over men leads towards the deprivation and crisis of system when majority of population is not given education facility equally how we can develop socio-economically. To regulate the social behaviors, the promotion of women's education is essential to be improved. Improving women's educational level has always been exhibited clearly the impacts not only economical but also health of the future of youth, which obviously influences the entire community. Another advantage of promotion of female education is they can assist the males economically because the education also provides the earning opportunities to the people if females will be educated they will have access over job opportunities. This is co-relational study between two major variables civilization and women education while using deductive research approach. Obvious fact is that all civilized and developed countries bestowed the importance of women's education.
\end{abstract}

Keywords: Education, Women, Society, Culture

\section{Introduction:}

Education is taken from Latin word, Educare that meaning is to nourish, to train or Educere meaning is to lead someone. So through this we can understand that education is external and always impose from the outer world. ${ }^{1}$

The purpose of education is to improve the standard of human in a special time triumph, as well as self awareness, knowledge and ability to make the people who are lower end of circulation fabrication lies at the middle they may wish for attempt to reduce poverty. ${ }^{2}$

Organizational, managerial, and administrative skills are acquired by individual through education. Additionally, it is the result of education as well that it improvesself esteem and uplifts socio-financial status within a community. So there may need to endorse 
education system especially for women and that will leads the Pakistan towards gender equality and human development, We cannot rebuff worth education of female becauseleducation of female at lower always impact pessimistic collision on growth of economic of Pakistan as it also affects thehuman capital. It is stated that education of female diminishes fertility, infant mortality and also increases education level of childrenin developing countries. The research paper is written for the better understanding about the impotence of women's education in society and enhanced the level of economic development leading towards civilization.

It is not easy to debate with the inference that the idea in the wake of the formation and progress of individual life is fundamentally demonstration of individual civilization regarding elevated plinth of development, throughout an enduring procedure. Thus history of individual gives evidence acquaintance is the basic factor of development of human that enables to insert worth to cultured life. Conception is gained through education and human history showed that only unusual and small number of cases has been endowed by means of the competency for getting knowledge throughout perception.

Those communities, whose highlight influences of education historically flourished in evaluation by means of those who appreciate reassure of unawareness, impound to a shelter of kind sluggishness that delay expansion. It has been requirement of independent State to be familiar with education as a right of the civilian since the societies developed into states. However education as for as possible is always encouraged by the state. In second millennium Muslim scholars with respect to early centuries the globe apprehended is individuals' nature to spotlight on human as well as enquiry humanity during human life and the concern atmosphere because it make possible for people to accomplish status of acquaintance that it finds itself able with today. It is not possible for societies and States in the direction of desire and takes action for altering requirements of enlargement not only to endow individually, materially and socially regarding education but also to get on a conduit of advancement in addition to apprehend their potential as the citizens of nations.

Therefore, education and knowledge attainment is the engine of progress which is undeniable driver for any nation. The founders and the fathers of Pakistan was acquainted with untimely the upcoming time of nation of Pakistani is relied on an industrious detection of information which can be achieved through education. The Quaid-i-Azam expressed the importance of education during the first Education Conference held in November 1947 in his speech: 
"We must bring our educational policy and program on the lines suited to the intellectual people, concert with our history and culture and having regard to the modern conditions and vast development that have taken place all over the world if we are to make speedy, real and considerable progress. The future of our State or nation will and ought to accordingly depend upon the type of education which we are giving to our children, and the way in which we bring them up as future citizens of Pakistan. We should try to inspire into them the high sense of honor, integrity, responsibility and selfless service by sound education to the nation. Scientific and technical education to our people is essential as an urgent and immediate requirement for giving in order to build up our future economic life and to see that our people take to science, commerce, trade and particularly well planned industries. We should have to remember it always that we have to fight with the world which is moving very fast in this direction." 3

We cannot refute the magnitude of education in all sectors of society. Today's advancement and the development are not possible without improvement of education system at social, economic, political level in any region or country. Society consists upon with the combination of both genders male and female; females are almost 57 percent in Pakistan this ratio of females is not ignorable for the development of area. But it is pity that females are not encouraged regarding education especially in Southern Punjab of Pakistan.

The conservative and orthodox approaches do not allow the females to join educational system properly. Females are supposed to be stay at home for dealing domestic affairs. If the females are educated they will assist the males in all aspects of life. Female education is very important for today's survival and development of Pakistan. Economic growth with special regards with the human capital is negatively influenced by lower level of female education. Economists at developmental level explained the education of females has direct influence on fertility, mortality of infant control and enhance the level education of children. System of education has great influence on the development of any nation as well as the educational system is designed on the requirement of social needs. Today development is not possible without the coordination between both genders male and female in society. But it is a real approach the females or girls are deprived in educational attainment; they have to face many socio-cultural, economical and religious issues in Pakistan. 
The impact of education on personality development, it is said that education is usually supposed to be the next mainly imperative pressure for determining of individuality after the parents duties. After admission of the students in schools result indicates the early school child always starts to absorb the standards of his communal requirement. ${ }^{4}$

The interest to stress on the progress of higher education within particular behavior and obliging procedures for the advantage of diverse social groups named by the castes, sections and women. They also evaluated the instructional rule study which distributed some roles to sophisticated education. The result proved that the educational policy be unsuccessful to give those occupation which remain sectarian aims even at the theoretical level. ${ }^{5}$

The factor which are influencing on economical growth in Pakistan is regarding discrimination of gender issues. The researcher used methods for data collection on related issues by secondary source of time series. Economic growth significantly influenced by these variables including the educational ratio, enrollment, rate of literate female over male were thekey variables at the endit was concluded that discrimination between gender in primary education can eliminate the economic growth. Through an another empirical study, The features which influence the poverty rate in rural area of Southern Punjab Pakistan, realized that the reasons of povertycan be eliminating through these factorslowering the household size and dependency ratio, increasing female labor participationand improving education.

Results pointed out that the poverty line is directly related with the variables of dependency level and household size.Education has the meaningful contrary relationship with poverty because of enhancing the opportunities of employment and snubs poverty. ThePakistan is ranked from 146 countries situated at 120 in regards of Gender related Development Index (GDI) and with reference to Gender Empowerment Measurement (GEM) ranking Pakistan is ranked position of 92 out of 94 countries according to UNDP 2010 report.

There are different strategies to measure the gender inequity in education. The important tools are Grossand net enrollment rates and completion and dropout rates to classify the gender inequality in education.Higherallocation of resources on the education of women can leads towards the resolve the concept of gender disparity at all levels of education including sturdygender disparities subsist in attainment of education level and literacy level between rural and urban areas of Pakistan.

Yet it's not an easy task to give details about the magnitude of education for both individual and society as it might seem very simple and easy. Because at the First level it is supposed that advantages of instruction are extensive, related with the importance of market 
and non market regions, these things are also potentially in clash. Education possibly will direct to accomplish in various areas of societal ethics, except it is not likely to perform so across all fields of society in equivalent determine, for instance, if a person devotes time to actions in one task that acquire this person as of instant devotion to actions in another role.

At the second level, it might be possible that education be able to bring happiness or pleasure to a person but at the same time there is no assurance that it will bring happiness and pleasure to others. Definitely, there is need to think what kind of things can compose the education attractive and what type of techniques can be implicated which allow the individual to shape and track their private purposes and aspirations fairly separately as of the requirements and happiness of others. It is seldom recognized individuals may perform negative implications for others into detection of existence whether penetrating in favor of like healthier occupation, an innovative association or more wealth.

Thirdly, it is not clear the standard of empirical expression of education, like schooling is merely associated with these varied social results and the causes of changes in these results. At the same time as a substantial part in investigation has cross-examined the influence of coaching on outcomes of market, particularly earnings, in illumination of the accepted determinant of schooling. The consequences of schooling on societal products encompass not issue to the similar stage of pragmatic inspection yet although numerous of equivalent problems affect. For instance, this is rising proof that social responsibility of grown person has roots regarding expansion, it is suggested a large amount of comprises helpful and demonstrative personality is resolute well before education of schooling is completed. ${ }^{6}$

Skills regarding teaching, knowledge of instilling and dispositions of encouragement reputation the precepts of freedoms of legitimate and errands can achieve the major purpose of public schools that is to produce the active and good citizens for the development of society. ${ }^{7}$

Whether rivalry inside the sector of public school and competition from private schools positively influence the school of public sector productivity along with another time diverse form or categories of outlays impinge on another way. This discovers normally considerable affirmative consequences of competition with private for few evaluates of output of school nevertheless slightly. ${ }^{8}$

The relationship or association is involving income of family and achievement of education almost the entire levels of coaching. The data showed people with small amount of income are always gives less preference to get education from high standard of schools. 
They also used facts found straightforwardly through a munificent school of skill center so as to sustain occupied guidance financial support syllabus, it endows with straightforward indication so as to environment of family causes to are unconnected toward guidance expenditure of college be extremely imperative. The outcomes of this research suggested that significant distinctions in attainment of qualification will survive still condition joining of tuition centre is nothing for all children had conclusions on behalf of selective programs of course of action. ${ }^{9}$

Education is playing vital and crucial role in society it can be said that no human beings are able to survive properly without education. In fact education tells us how to think, how to work properly, how to make decision in our daily life. It is most important in life like our basic need foods, clothe and shelter. Being sociologists we believe that human is a social animal and cannot live alone, through education we learnt the social behaviors like how to work together with others, how to build the friendship with others.

For the purpose of getting education at the beginning the parents enroll their children in school for not only to learn the alphabets and numbers but also for developing their confidence and personality. Children while making friends, with further development they are faced with the sense of competition and desire and other such emotions and feelings. There they also learnt to control these emotions and feelings in school. The teachers educate the children how to act in different situations. So we can say that schooling is the basic unit of education. In the modern era of education we divided the school education system into two major types, private and public, both are different in nature and have different effects on the educational attainment as well as personality.

These personality traits and educational attainments create the hurdles and problems to the students during education. The present research was conducted to highlight the issues of female education at school level. Females are the first agent of socialization for the children and if they will not educate, they cannot socialize the children in a proper way or according to societal needs.

\section{Significance of Education:}

Scientists who are working on various issues are taking positive when they peep in the education sectors of human and work to improve their standard. Purpose of education is to improve the standard of human in a special time triumph, as well as self awareness, knowledge and ability to make the people who are lower end of circulation fabrication lies at the middle they may wish for attempt to reduce poverty. ${ }^{10}$ 
Education is an essentially system through which a person in social life develops into knowledgeable of leading an ethical and communal life, the individual becomes a mechanism of cheerfulness for himself. Modern pragmatic investigation established links of the coaching section at school level of education through results interrelated to at slightest several of these states. $^{11}$

Education is typically symbolized by means of time or else rank of schooling accomplished in experiential work. It has extensive interest in a great deal of prose on practical as well as strategy correlated improvement. Mainly, it is said that the pragmatic proof for better public policy is very strong supported for schooling in developing countries. The eccentric protracted revolutions are often considered strongly support substantial public subsidies for schooling in developing countries to best attain their goals in many of the economies of Southeast and East Asia. ${ }^{12}$

\section{Different conception of Education}

The term education is elaborated in different perspectives according to the view of the person. It will be easy to understand the diversity of education if we can comprehend the meaning and the concept of education in appropriate manners.

\section{(a) Education is the achievement of Knowledge:}

If we define the education as love of knowledge its mean we are talking about the acquisition of knowledge. A very great Greek Philosopher Socrates tells that "Knowledge is Virtue" and who has knowledge is called righteous. According to Francis Bacon "the knowledge is Power and the knowledge of the universe around is instrumental for the progress of the society." So according to above mentioned discussions we can say that Knowledge has its worth from history of Education to till now in this system of education also.

\section{(b) Education is the Tool of Intellectual Discipline:}

The English philosopher John Locke, from the Sixteenth century perceived that mind with the part of functioning different components including, Imagination, memory and thinking pattern. The faculty of psychology always believes in this concept of mind and its components as well. Child is born with clean slate mind; the development of these components is called the mental development of child. The mind of children is just like the plastic or a flexible, it is developed by the direction of your curve. So according to this education is the method or a training to mold and bend these faculties (components) of mind on the need of the children. 


\section{(c) Life preparation Through Education:}

To spend a successful life is the strong urge of the human being. Reason is that the successful life always eliminates the undesirable issues from life while using the skills and enhances the ability of the men. Successful life included the healthy, wealthy, married, having good socialization of the children, create cooperative and peaceful environment round them. While trying to spend a successful life one have to face many problems. In this situation, he has to have enough knowledge and skill, framework attitudinal and behavior those are necessary for problem solution.

\section{(d) Education is the Transmission of Culture:}

Above mentioned points explains the individual personal training is education but when we talk about the social level education is the transmission of culture actually. J.S. Mill referred to the education "Education is the culture which each generation purposely gives to those who are to be its successors, in order to qualify them for at least keeping and if possible for rising, the level of improvement which has been maintained." Two major points can be noted through this definition, education is playing role in preservation of cultural traits. The main goal of our activities is to preserve our culture. In Pakistan, the promotion of culture is in the hand of our youth, if we deny this situation and fellow the others culture its mean we will destroy our nation through our own hands. The second point is that there is no culture which we can say is the perfect, so there is need to refine the culture according to the need and situation of the society.

\section{(e) Education is a Direction:}

It is fact that children come to school having no maturity and after getting admission in school they will be able to mature their abilities, capabilities and level of interests. This is basically the duty of the school to direct the need base development of the children and according to personality. So the education is important to plan the direction of all the aspects of the children's personality. ${ }^{13}$

\section{Role of Education in Socialization:}

We can divide the types of activities of men into two parts one is organized and second is random. Random activities have nothing in mind but the organized activities are always planned in mind and obvious direction of any action. These directions are the purposes of decided actions. These purposes are determined by our social, cultural, economic conditions of our surrounding. 


\section{Aims are determined by Factors:}

Attainment of educational level is always influenced by different factors in the society. We cannot explain them in a simple line or a sentence. The factors are the following: Political Ideology:

Democratic, totalitarian, and communistic are the form of government which has different aims of education. Every political government brings its own ideology and interest of education.

\section{Socio-economic issues:}

Every social and economic issues of any country is addressed by the education system, these problems only solved by the educational system.

\section{Philosophy of Life:}

We have different philosophy of education Naturalistic, Idealistic and pragmatist in education; it is used by the need of the society. All the system has its own strategy according to the societal need.

John Locke was a English man period from 1632-1704 his contribution can be understood through his easy published in 1690 "An Essay Concerning Human Understanding" wanted to highlight the acquisition ideas is how important for human beings. Locke said that at the time of birth human mind is just like a blank slate after the birth he learns from the outer world while using the senses and understand the environment around them. Comparison, generalization and reflections of the things convert the simple ideas to the complex one. According to him, learning is an active process in which through senses a person gets knowledge from the outer world and experience. ${ }^{14}$

The influential work of French theorist Jean J. Rousseau 1712-1778 "The Natural Person" he had worked a lot on socio-political as well as the educational paradigm but was famous by his work on Socio-Educational part. His contribution "On Origin of the inequality of Mankind and the social contract, this elaborates the discrimination and difference on the basis of wealth, property and prestige these are the main causes of ascend of social imbalance are reproduction in a fake way. According to him, all the humankind has naturally noble savage and innocent free persons. It is our society that indulges the human being into the unequal differences according to its own interest. The natural freedom of thinking and personality development has been exploited and societal corruption become dominant over there. He notified the five stages of growth including infancy, childhood, boyhood, adolescence, and youth, while explaining these stages he said that all stages have its own strategies for growth, especially the early stages are more sensitive and important should be 
free from the societal corruption. The nature and free environment is important for the good growth and development for the children education system should be introduced according to the interest and the need of the childhood stage. ${ }^{15}$

Johann Heinrich Pestalozzi a Swiss educator time period from 1746 to 1827 was the follower of the Rousseau, he encouraged the work of him while using these words that human being such a noble and innocent creature of the God but the system spoil him and make him corrupted. He also said that pedagogical techniques can sort out and polish the personalities of the human being after removing the traditional or orthodox mess of memorizing and recitation of things. He said children should have to learn in natural environment with the support of natural objects just like for understanding the counting the students have been taught in the nature environment and with the use of pebbles and beans when they will recognize the basics of mathematics then teachers should have to introduce with the numeric digits and develop the relation with the earlier knowledge regarding mathematics. Simple is that the learning process will be shifted from natural simple system to the complex system of education. ${ }^{16}$

A social theorist name Herbert Spencer 1820-1903 was an English man adopted the theory of Darwin and related this concept to the social as well as the educational setup. Darwin said that all the species change themselves gradually or step by step according to the need of them, so all the system in society are also changing on this theory. This is called the survival of fittest in the world. So Spencer also said that societal things are also changing form simple to complex and most general to more specific. He also supported the work of Pestalozzi while using the situation that learning of the students should be started from natural objects in which they are living. This is the best way of utilizing the things. ${ }^{17}$

The importance of socialization can be recognized that is the process of learning and understanding the normative pattern of the every human society. Without this the human beings will not be able to develop the human characteristics and even to participate on group life. This socialization process leads towards the personality development of the individual after learning the norms and values from the society. It is clear that the results of socialization show in the form of personality of the individual, which consists upon the feelings, emotions, thoughts and actions of individuals. The concept of personality is driven from the self which is a personal identity of persons which they collect from the consciously experiences and distinguishing from other people. The project was conducted to check the impact of teacher's attitude on the personality of the students. Teacher is the important status, given by society, playing very essential and crucial role in the socialization of the children. This socialization is 
stared from the day when the parents of the children enroll them in the schools. They personality and the behavior of the teachers influenced the personality traits of the students. Different theories were given or introduced on the personality development of the individual from different discipline but the researcher found suitable the theory of Charles Horton Cooley, George Herbert Mead and Sigmund Freud for this research.

Charles Horton Cooley said that children learn about themselves after understanding the others reaction towards them. They learn in their company of family and friends those focus on themselves easily. From this approach children learn to evaluate themselves in terms of how they visualize others react to them. Here people are like mirror for the improvement of personality. The thinking is direct related how others are thinking about them when they act or behave in a particular way. This way of learning is called looking glass self by Cooley. This theory consists upon three main constantly stages:

1. The visualize our appearance to others

2. The envisage the response of others to our visualized appearance

3. The evaluation of ourselves on the basis of our visualized appearance from others.

After these constant stages the outcome of this procedure is may be positive or negative feelings about us. So, on the basis of these positive and negative feelings we develop our personality.

The process of looking self might be reflected true about our personality or might be not because it takes place in the mind and being the product of our imagination. In spite of this reality the possibility of this, self and others is well established.

The researcher selected this theory because it develops the relationship of personality and showed the interaction between the human organism and the social forces. This social environment is as important as other agents of socialization in the childhood socialization process. In the development process of ego and superego of the children parents and the teachers are the pillar and fundamental characters. Without their full support and perfect strategy the personality of the child cannot groom perfectly. In this research the researcher wanted to check the effect of teacher's way of teaching, talking flexibility and the discussion on study matters with students on the personality of the students at school level. ${ }^{18}$

Whether rivalry inside the sector of public school and competition from private schools positively influence the school of public sector productivity along with another time diverse form or categories of outlays impinge on another way. This discovers normally considerable affirmative consequences of competition with private for few evaluates of 
output of school nevertheless slightly. There is sturdy proof school of public sector attention along with be short of public rivalry might be reduced discipline productivity. It also accomplished to discover discrepancy consequence regarding instructional opposed to noninstructional expenses, on the basis of the measure of productivity utilization. Meant this amount produced determine like completion of rates regarding school constant by means of the proposal individuals overshadowing result possibly will favor previous to final, nevertheless this does not show to be the case for the percent of students getting high quality state wide regents diplomas. ${ }^{19}$

Scientific research on thought has grown extensively over the past thirty years. Observed in countless readings disclose advantageous outcomes in immune response, brain functioning and in general well being trait to thought. Further parts of exploration and relevance thoughtful practices deals with the co-curricular activities such as contain exertion in organizational management, performance of sporty, social justice and a variety of other fields. An education which should get better this faculty that willingly bringing back an itinerant attention over and over again would be the education parity excellence. The work indicated postulation coaching thought method of studentswill augment the capability of the teachers to divert their mind in a controlled and conscious mode. This has been suggested that these type of practices always support in the process of decreasing stress of scholastic furthermore an in general nurturing of entire being the substantiation as of this work recommends a on the whole affirmative manipulation academic performance of student and on realizing conventional scholastic goals as significant philosophy. ${ }^{20}$

The impact of education on personality development, they said that education is usually supposed to be the next mainly imperative pressure for determining of individuality after the parents duties. After admission of the students in schools result indicates the early school child always starts to absorb the standards of his communal requirement. This paper focused on the relationship of the teachers and the pupils. The affiliation between instructor and student during class with the support of course data which is obtainable mutually correspond to strong manipulates in the fortitude of person positions of sight, intellectual strength, and general individuality prototype. No one can refute the fact that the teacher facilitates the students to find out the reward that could be resultant from an understanding of at slightest various form of accepted experiences of the universe. ${ }^{21}$

\section{Importance of Women's Education:}

The main concern of this research project is that through the improvement of girl's education, we can have power over the hurdles of society and eliminate the social evils in 
Pakistan. Female direct involves in the process of socialization of children, she can play a vital role in this regard of promoting peace in society. As well as we can ignore the ratio of females over males in Pakistan so when majority of population is not given education facility how we can develop socio-economically. Females can assist the males economically because the education also provides the earning opportunities to the people if females will be educated they will have access over job opportunities.

Context, definition, assumptions, and implications of the educational system for the development of children education are important. In order to understand the schooling the library as well as field research was conducted. The result showed competency of social and imitates the amplification of disparity of social life escorts toward private schooling system. It also showed that the interest of wealthy parents to schools. The changes in education designs set of courses, coaching, liability, along with management of school is changed through different schools system. The great dissimilarity involving private disciplines and the public equivalent points out so as to the influential discipline of private mostly provide the requirements with respect to the reasonably confidential cluster. The research was conducted to take the answers of the with the intention of discipline private schools only attempt in the direction of best educational quality in favor of a communal good and implies with the development of private schooling the concepts of value conflict emerged. Therefore it is very much cleared revival of these schools might include a smaller amount of effect regarding equity and quality of schooling however instead of stratification of social life. The material was selected through both sides the research within library included by newspapers, documents of government, popular and general professional material as well as the field research by talking about teachers about policy, strategies and public attitudes. ${ }^{22}$

The education which in pragmatic work is usually corresponded to by years of schooling done was momentous notice in much of the works on functional and policy related development. The objective of this paper is to repeat the question of the degree to which such entitlements are essential constructed on accessible experiential signal. The pragmatic effects of schooling it is needed to imitate the three way basics for good realistic study in the exact circumstances of the issues and impact of funds in human belongings and connected strategy issues concept, data, and assessment. These three magnitudes of experiential investigated in the social sciences are disapprovingly consistent. The theory offers basis for logically discovering quite a few magnitudes of the factors and impact of human. ${ }^{23}$

The variation to estimate the relationship between many outcomes in early development and participation of life in a single parent family is developed during childish. The scrutiny 
was completed using a unique sample of young adults who are selected from the first five sides of the British Household Panel Survey and can be equivalent with at least one familial over the same period. They find that information of life in a single parent family was usually related with damaging consequences for young adults most of the negative outcomes were connected to an early family disruption when the child was aged less than five year and level approximations whose fundamental amplification depends on sturdier hope approve the previous outcomes and show that for most results the contrasting family structure consequence perseveres even after authoritarian for the pecuniary situations of the family of structure. $^{24}$

The parents and family education have put a lot of effect on the development of child's. Wealth has been a mark that positive association between education of their parents, particularly education of mother, and generally children's education. The main target of such policies was the child's education has been increased and reduced educational inequality. The parental effect has not been directed due to income effect. The researcher explained that parents education have been positive effect on their children's schooling attainments while the step parents negative impact on children's education. They concluded that increase in parental education and by improving skills of their parents or simply change the worth that parents have been attached to the education of their children. The children who have greater thirst for education did not increased their schooling achievement after the change in order to provide a indication of their ability, only children who have low level of schooling would have increased in their education when affected by the change. ${ }^{25}$

The parents can choose the best schools for their children, how many economic standards foresee parents would play a good role when choosing schools for their children as compared to those who are experts in government agencies. Experiential research of three types are conducted, related to the hypothesis are reviewed. The first was the surveys showing that parents rate schools the same as experts, second surveys showing that most parents selects schools on the basis of their perceived academic quality and third data showing student academic achievement gains are higher in schools of choice than in traditional public schools. ${ }^{26}$

The effect of parental considerable background put such consequence on their child such as skills of cognition, edification, fitness and income of consequent and also the economic status has been positively associated through generations. Link involving the parental schooling with children might accede to early age leave school caused by difference in enduring revenue, level of education of the parents and stuns to income. Individual education 
as well as the education plus incomes of children's parents and scrutiny supported are on Survey of Labor Force that was quarterly sample of households. They concluded so as to the sturdy outcomes of education of parents develop into non significant and unending maters of income. Their findings have been an important implication to design such policies aimed to encourage the young learners to remain in school for longer.

The primary goals of public schools are to promote adult engagement of community. The very important and essential enthusiasm for overtlyafforded of schooling is the unenthusiasticinfluence of schooling regarding private sector on engagement of community. He conducted proportional results of extensive (Catholic) and high school of public sector on young supporter contribution moreover unpaid assistants in U.S. The result showed with the purpose of pupils those admitted the extensive schools of high level were really extra probable to choose like young. The vigorous to conditioningon were estimated influences were affluent set of traits of person, relatives and neighborhood. He presented double steps smallest amount estimates that supply reminiscent proof that favoritism is the results are not due to selection. ${ }^{27}$

To investigate the intergenerational schooling transmission differs transversely in residents groups. In the study it was depicted that were not same characteristics in learning diffusion athwart the groups of population. On other hand it also checked up the models of economic educational victory that was given the elucidation the experimental patterns of movement in status. The major variables of present research were the diffusion in intergenerational, accomplishment of education, and succeeding generation refugees. It was scrutinized that the economic theory can throw in to make clear the patterns of intergenerational education transmission. ${ }^{28}$

Study the most important issues of the schools. That was very crucial component of developing biasness victorious in studies due to biasness endeavors to boost scales of correspondence connecting undertaking and achievement. He said that purpose or objectives of schools of public should elucidate minimum level and redefined maximum level in given epoch so that the father and mothers have enlarged their educational choices of pupils. This mission regarding public schools cannot be underestimated so that the magnitude developing shared and understandings of the crucial ideas could be reasonable. This whitepaper pointed the promotion of such operation. The instigator recommended so as to it is decisive to redefine the mission of schools to the parents in array to guarantee the fundamental maneuver of schools don't delayed in throw away if the mission of public schools confused or unrelated in these times. The author said that there is need to clarify the fundamental idea of the 
purpose of schools and meeting the effort for maximum effectiveness on the capitals or resources. Therefore, the solution of this paper was not that the instructors should have to note that increased funding at hand in this whitepaper ${ }^{29}$.

The education has been ignored in many developing countries we know the reality regarding the importance of development in countryside area; we are still unsuccessful while achieving this result accomplishment. It is cleared that the problems in countryside areas regarding education were not only correlated to the quantity the nation expends to the system of education or on education. The other variables which affect the education system in rural areas are social as well as the economic condition of the individuals belong to the rural sector moreover structure of education in rural area as well cooperate an important ingredient. The current lesson covenants to the social and financial features with the purpose of manipulate the achieved educational echelon. This research exertion is divided into triple major pieces first is the educational state in countryside areas second is the aspect harmfully influencing an decision of individual to prolong at school and the last one is the persons who cannot go ahead in their studies might be due to their unemployment. There are some types of recommendation to provide employment so that the y useful citizen, they should be facilitated to attained seminars and workshops which are helpful to get job in future in the lights of results of this research. ${ }^{30}$

The unconstructive correlation at strong level that to be the part of linking schooling andteenage children socialization, the main part of this follow a line of investigation was there was causal relation exist along with this correlation correspond. The modifications related with schooling obligatoryedicts are used in this paper in Great Britain and Northern Ireland to wash out approximation of schoolingfavoritism which always consequential from specification of individual fault apparatus correlatedwith education. There are significant consequences that advocate that there is there may exists correlation among the two important variables of this research just like when schooling increased come into sight teenage childbearing will be reduced. ${ }^{31}$

The great impact of schooling on social unity (cohesion) as well as the impact of coaching on community results encompassed not expected with the equivalent severity like the impacts of coaching on market of employment results such as bring in Particularly (i) family education, instinctive characteristics and personality are such potential and frequently unnoticed bewildering factors that manipulating mutually social outcomes and schooling and (ii) the modes in which schooling shoves persons in numerous tracks at the same time but also in the direction of more independent and market driven searches. This exploration 
discovered the consequences of schooling on events of public rendezvous and community associations and labor force paid and labor force membership by via models of dissimilar personality identical twins as well as ordinary siblings. At one level, the outcomes revealed healthy affirmative achieve of schooling on earnings the hypothesis was that the persons who get the well level of education will work more and earn more. At other level the results divulge additional weaken and seldom unenthusiastic impacts of schooling on communal results. Definitely schooling may possibly to encourage some for social behaviors but individuals have choice of pursuing more personal interests from schooling. ${ }^{32}$

\section{Conclusion:}

Society consists upon with the combination of both genders male and female females are almost 57 percent in Pakistan this ratio of females is not ignorable for the development of area and for civilization process. But it is pity that females are not encouraged regarding education especially in Pakistan. The conservative and orthodox approaches do not allow the girls to join educational system properly. Girls are supposed to be stay at home for dealing domestic affairs. If the females are educated they will assist the males in all aspects of life. Female education is very important for today's survival and civilization of Pakistan.

Economic growth with special regards with the human capital is negatively influenced by lower level of female education. Economists at developmental level explained the education of females has direct influence on fertility, mortality of infant control and enhance the level education of children. System of education has great influence on the development of any nation as well as the educational system is designed on the requirement of social needs. Today development is not possible without the coordination between both genders male and female in society. But it is a real approach the females or girls are deprived in educational attainment; they have to face many socio-cultural, economical and religious issues in Pakistan.

In this time period of terrorism in our country, the socialization of the children is important for controlling this unwanted circumstance. If mother will be educated the children's socialization will be better and according to societal needs. Socialization is the process of converting persons into the society. This is two ways process where both the learner and the facilitator improve themselves. This project is designed to improve the girls education and aware the people regarding the importance of girl's education in our country. Education is the process of training of the student through proper channel and academic environment. 
Different theories are attached with the role of teachers and the personality of the students. Many psychologists and sociologists worked on it and elaborate the relationship of personality development of the children and the pedagogical techniques of the teachers as well as teacher's behavior also influence the student's performance of education and personality.

In this research project the work of many educationalists also elaborated for the better understanding of the role of education in the process of socialization of the children. They have different perspective of explaining the educational phenomena. Some said the child born very innocent, it is our educational system that makes them positive or negative. So the educational system should be student oriented and students should be provided natural environment for learning. Some said the natural environment is easy for learning and simple, we should have to move from simple to complex structure system of learning.

For this research project the selected module and activity chart is designed, at the first level survey was conducted to understand the issues of the low girl's education in areas. The result showed that parent's illiteracy rate and the lack of awareness regarding promotion of girl's education were the reasons of low level of girl's education. At the second stage, the seminars were conducted to give the awareness to the local people towards the importance and the development of the girl's education. The girl's education is important in various points.

- The children socialization will be according to the societal need

- The domestic affairs will be resolved in better way

- The human potential of females will be used in positive way

- The economic development of the community/country will be progressive

- The behavior of the human being will be controlled

These are the consequences after promotion of girl's education. The development of any country is not possible while the mothers are not educated there. So this sentence makes clear that educated mothers can build a strong nation and citizens. 


\section{References:}

1 Shahid, S.M. (2006). History and Philosophy of Education. Majeed Book Depot

2 Pallas, Aaron M. (2000). The effects of schooling on individual lives: Hallinan, Maureen T. (Ed.), Handbook of the Sociology of Education, Vol. 499-526. Kluwer Academic/ Plenum Publishers New York.

3 Aly, Javed Hasan. 2007. "Education in Pakistan: A white paper."

4 Thorpe, Louis P and Schmuller, Allen M. 1958. "Education as a determinant of personality formation." Pp. 178-209.

5 Chanana, K. 1993. "Accessing higher education: the dilemma of schooling women, minorities, Scheduled Castes and Scheduled Tribes in contemporary India." Vol. 26, Pp. 69-92.

6 Jacobs, Jerry A. and Gerson, K. 2004. The Time Divide: Work, Family, and Gender Inequality: Harvard University Press, Cambridge, MA.

7 Hess, F. 2004. "What is a public school? Principles for a new century." Journal Clashing views on educational issues, Pp.152-160.

8 Greene, Kenneth V. and Kang, B. 2004. "The effect of public and private competition on high school outputs in New York State." Pp.497-506.

9 Stinebrickner, Todd R. and Stinebrickner, R. 1998. "The relationship between family income and schooling attainment:Evidence from a liberal arts college with a full tuition subsidy program."

10 Pallas, Aaron M. 2000. The effects of schooling on individual lives: Hallinan, Maureen T. (Ed.), Handbook of the Sociology of Education, Vol. 499-526. Kluwer Academic/Plenum Publishers New York.

Durkheim, Emile. 1956. Education and Sociology: The Free Press, Glencoe, IL

Behrman, Jere R. 1999. "Schooling in Asia Selected micro evidence on determinants, effects, and policy implication." Journal of Asian Economics, Vol. 10, Pp.147-194. 23.

Locke. J. 1959. “An Essay Concerning Human Understanding.” Alexander Fraser New York.

15 Rousseau, J. 1964. “The first and second discourses, St. Martin's New York.

16 Pestalozzi, J. 1900. "How Gertrude Teaches Her Children, trans." Holland and F.C. Turner New York.

17 Hofstadter, Richard. 1955. "Social Darwinism in American Thought." Beacon Press Boston.

18 Burger, Jerry M. 1990. Personality, $2^{\text {nd }}$ edition. Wadsworth Belmont, colifornia United State of America press.

19 Greene, Kenneth V. and Kang, B. 2004. "The effect of public and private competition on high school outputs in New York State.” Pp.497-506.

20 Helber, C. et al 2012. "Meditation in Higher Education: Does it Enhance Cognition?"Vol. 37, Pp. 349-358. 
21 Thorpe, Louis $\mathrm{P}$ and Schmuller, Allen M. 1958. "Education as a determinant of personality formation." Pp. 178-209.

22 Cheng, H. and Delany, B. 1999. "Quality Education and Social Stratification: The Paradox of Private Schooling in China." Vol. 1.

23 Behrman, Jere R. 1999. "Schooling in Asia Selected micro evidence on determinants, effects, and policy implication." Journal of Asian Economics, Vol. 10, Pp.147-194.

24 Ermisch, John F. and Francesconi, M. 2001. "Family Structure and Children's Achievements." Journal of Population Economics, Vol. 14, Pp. 249-270.

25 Chevalier, A. 2004. "Parental Education and Child's Education: A Natural Experiment."Forschungsinstitute zur Zukunft der Arbeit Institute for the Study of Labor.

26 Bast, Joseph L. and Walberg, Herbert J. 2004. "Can parents choose the best schools for their children?" Vol. 23, Pp. 431-440.

27 Dee, Thomas S. 2005. "The Effects of Catholic Schooling on Civic Participation."Vol. 12, Pp.605-625.

28 Bauer, P. and Riphahn, Regina T. 2007. "Heterogeneity in the intergenerational transmission of educational attainment: evidence from Switzerland on natives and second-generation immigrants." Journal of Population Economics, Vol. 20, Pp. 121-148.

29 Scott, Stephanie T. 2008. "Redefining Public Schools."

30 Olgun, A. et al 2009. "Schooling and Factors Affecting Decisions on Schooling by Household Members in the Rural Areas of Turkey."

31 Silles, Mary A. 2010. "The effect of schooling on teenage childbearing: evidence using changes in compulsory education laws."

32 Schnittker, J and Behrman, J. 2011. "Learning to do well or learning to do good? Estimating the effects of schooling on civic engagement, social cohesion, and labor market outcomes in the presence of endowments." 